\title{
ANATOMIA DA MADEIRA DE VACHELLIA FARNESIANA (L.) WIGHT \& ARN. ${ }^{1}$
}

\author{
JOSÉ NEWTON CARDOSO MARCHIORI ${ }^{2}$
}

\section{RESUMO}

A madeira de Vachellia farnesiana (L.) Wight \& Arn. é anatomicamente descrita, com base em amostras procedentes do Rio Grande do Sul. A estrutura anatômica assemelha-se ao descrito para Vachelia caven e $V$. ibirocayensis, aliando fibras não septadas e de paredes espessas, contrastantes com o parênquima axial, a séries parenquimáticas de 2, raro 3 células. A identificação de Vachellia farnesiana requer o exame de caracteres quantitativos, salientando-se o comprimento de elementos vasculares, o diâmetro dos cristais no parênquima axial e a freqüência de raios.

Palavras-chave: Vachellia farnesiana, Acacia farnesiana, Fabaceae, Leguminosae Mimosoideae, anatomia da madeira.

\section{SUMMARY}

[Wood anatomy of Vachellia farnesiana (L.) Wight \& Arn.].

The wood anatomy of Vachellia farnesiana (L.) Wight \& Arn. is furnished, based on samples from Rio Grande do Sul state, Brazil. The anatomical structure agrees with literature references to the woods of Vachellia caven and V. ibirocayensis, joining thick walled non-septate fibres with axial parenchyma series composed by 2, rarely 3 cells. The identification of Vachellia farnesiana also requires the examination of some quantitative features, including vascular elements lenght, chrystals size and frequency of rays.

Key words: Vachellia farnesiana, Acacia farnesiana, Fabaceae, Leguminosae Mimosoideae, wood anatomy.

\section{INTRODUÇÃO}

Descrita inicialmente por Linnaeus (Mimosa farnesiana L.), a espécie em estudo figura em importantes monografias botânicas como Acacia farnesiana (L.) Willd. (Burkart, 1979; Cialdella, 1984; Izaguirre \& Beyhaut, 2003; Lorenzi, 1998), binômio amplamente utilizado ao longo do século XX, mesmo após a criação do gênero Vachellia (Wight \& Arn., 1834), do qual é a espécie tipo.

Recentemente, com a segregação do gênero Acacia (Tourn.) Miller e conseqüente reabilitação de Vachellia (Seigler \& Ebinger, 2006), tratamento seguido por diversos autores contemporâneos (Kodela \& Wilson, 2006; Banfi \&

1 Recebido em 12-V-2009 e aceito para publicação em 23-X-2009.

${ }^{2}$ Engenheiro Florestal, Dr., bolsista de Produtividade em Pesquisa (CNPq - Brasil), Professor Titular do Departamento de Ciências Florestais, Universidade Federal de Santa Maria, Santa Maria, RS, Brasil. marchiori@pq.cnpq.com.br
Galasso, 2008), o nome científico válido para a espécie passa a ser Vachellia farnesiana (L.) Wight \& Arn. A respeito do epíteto específico, cabe informar que ele presta homenagem ao Cardeal Farnese, introdutor da espécie na Itália, no ano de 1611 (Black, 1964).

Originária das Antilhas e norte da América do Sul (Burkart, 1979), Vachellia farnesiana também ocorre naturalmente em formações semidecíduas de terrenos calcários e pedregosos no Pantanal Matogrossense (Lorenzi, 1998), bem como no Paraguai, Argentina e Uruguai (Izaguirre \& Beyhaut, 2003). No Rio Grande do Sul, a espécie parece não ocorrer naturalmente, posto que Sobral et al. (2006) não a incluem em sua robusta obra sobre a flora arbórea e arborescente do Estado; o gênero Vachellia, deste modo, abrangeria apenas duas espécies nativas na flora gaúcha: Vachellia caven (Mol.) Seigler \& Ebinger, o popular espinilho, e $V$. ibirocayensis (Marchiori) Deble \& Marchiori, de ocorrência restrita à região do Ibirocai, no Planalto da Campanha. 
Muito ornamental, por sua vistosa floração, Vachellia farnesiana é cultivada em muitas partes do mundo e, no sul da França (Cote d'Azur) e Argélia, para a obtenção de "farnesol", óleo essencial de aroma idêntico ao da violeta, com largo emprego na perfuraria (Pio Corrêa, 1984). Cultivada em regiões tropicais e subtropicais do mundo, a planta é conhecida por rica sinonímia popular, destacando-se, no Brasil e região platina, os seguintes nomes: esponjeira (Burkart, 1979); coroa-christi, coronacris, esponja (Pio Corrêa, 1984); espinillo (Burkart, 1978); tusca, aromita e aromo (Cialdella, 1984).

Árvore pequena (até 7m) e espinhenta, de tronco curto e tortuoso, a espécie em estudo produz madeira dura, muito pesada $\left(1,04 \mathrm{~g} / \mathrm{cm}^{3}\right) \mathrm{e}$ de odor agradável (Lorenzi, 1998), com alburno branco-amarelado e cerne castanho-avermelhado, com veios longitudinais escuros. De boa durabilidade natural, contém de $7-13 \%$ de tanino, sendo comumente utilizada para lenha, carvão e cabo de ferramentas; troncos de dimensões adequadas, todavia, servem para dormentes, construção civil, esteios e corroçaria (Pio Corrêa, 1984).

Para o gênero Vachellia, a literatura anatômica dispõe de referências e/ou descrições das madeiras de V. caven (Cozzo, 1951; Marchiori, 1980, 1992; Tortorelli, 1956; Wiedenbrug, 1948) e V. ibirocayensis (Marchiori, 1993), tratadas, ambas as madeiras, como pertencentes ao gênero Acacia. Ainda não estudada, a partir de amostras da região, o presente trabalho visa a descrever os caracteres gerais, macroscópicos e microscópicos da madeira de Vachellia farnesiana, bem como comparar sua estrutura anatômica com a de espécies afins.

\section{MATERIAL E MÉTODOS}

O material estudado consiste de duas amostras de madeira, coletadas pessoalmente pelo autor e anexadas a coleções, com os seguintes registros:

- Marchiori, s/n, 28-IX-1985; pátio da Igreja São José (cultivada), Santa Maria, RS; HDCF 1835.
- Marchiori n. 962, 30-III-1989; Jaguari, RS (cultivada); xiloteca UFPR, n. 1505.

Das amostras de madeira foram extraídos 3 corpos-de-prova da parte mais externa do lenho, orientados para a obtenção de cortes nos três planos anatômicos. Do mesmo material também se obteve outro corpo-de-prova, destinado à maceração.

Os corpos-de-prova foram amolecidos por fervura em água e seccionados em micrótomo de deslizamento, regulado para a obtenção de cortes com espessura nominal de $20 \mu \mathrm{m}$. Usouse coloração com acridina-vermelha, crisoidina e azul-de-astra, desidratação em série alcoólica crescente $(25 \%, 50 \%, 75 \%, 90 \%, 95 \%$, duas vezes álcool absoluto), passagem dos cortes em xilol e montagem permanente, com Entellan. No caso do macerado, seguiu-se o método de Jeffrey (Burger \& Richter, 1991); para coloração, usouse apenas safranina $1 \%$ e, na montagem de lâminas, a mesma resina anteriormente citada.

As descrições anatômicas seguem a norma Copant (1973), com as alterações propostas por Burger (1979).

As fotografias de detalhes anatômicos (Figuras 1 e 2) foram tomadas em aparelho Carl Zeiss, no Laboratório de Anatomia da Madeira, da Universidade Federal do Paraná. Usou-se filme Neopan, ASA 100; as ampliações foram feitas em papel fotográfico Kodabromid F-3 brilhante.

\section{DESCRIÇÃO DA MADEIRA \\ Caracteres gerais:}

Cerne e alburno distintos; alburno estreito, amarelo-palha (HUE 2.5 Y 8/4) e cerne marrom-avermelhado claro (HUE 5 YR 6/4). Madeira macia ao corte transversal manual, de textura fina, grã inclinada a revessa, sem odor característico; figura resultante do arranjo do parênquima axial e fibras, em faixas tangenciais.

\section{Caracteres macroscópicos:}

Parênquima axial: visível a olho nu, abundante e paratraqueal zonado, compondo faixas irregulares de orientação predominantemente 
tangencial, menos tipicamente paratraqueal vasicêntrico, aliforme e confluente.

Raios: visíveis a olho nu em plano transversal, finos, pouco numerosos. Em plano tangencial, visíveis sem dificuldade sob lente, baixos, não estratificados. Espelhado pouco contrastado.

Poros: invisíveis a olho nu, pouco numerosos, de diâmetro pequeno, em múltiplos radiais e em cachos. Linhas vasculares irregulares, por vezes obstruídas por conteúdo vermelho-escuro, no cerne.

Camadas de crescimento: indistintas.

Outros caracteres: canais secretores axiais, máculas medulares, líber incluso, listrado de estratificação e canais secretores horizontais, ausentes.

\section{Caracteres microscópicos:}

Vasos: muito numerosos $\left(17-32-56 / \mathrm{mm}^{2}\right)$, ocupando aproximadamente $14 \%$ da seção transversal da madeira. Poros pequenos (55 $94-128 \mu \mathrm{m})$, de seção oval e paredes finas $(2,5$ $-3-4,5 \mu \mathrm{m})$, em distribuição difusa, não uniforme. Poros solitários e em numerosos múltiplos radiais e cachos (Figura 1A). Elementos vasculares muito curtos $(140-221-280 \mu \mathrm{m})$, com placas de perfuração simples, tendentes a transversais. Apêndices ausentes ou curtos (12 $-34-78 \mu \mathrm{m}$ ), em uma (Figura 1D) ou em ambas as extremidades. Espessamentos espiralados, ausentes. Pontoações intervasculares alternas, ovais ou poligonais, pequenas a médias $(6,5-7$ $-8 \mu \mathrm{m}$ ), ornamentadas; abertura lenticular, horizontal ou oblíqua, geralmente coalescente a numerosas pontoações. Pontoações raiovasculares e parênquimo-vasculares, pequenas e arredondadas, semelhantes às intervasculares. Goma, presente em numerosos vasos, no cerne; tilos, ausentes.

Parênquima axial: abundante, representando cerca de $27 \%$ do volume da madeira; paratraqueal, em faixas tangenciais e, com menor importância, nos arranjos vasicêntrico, aliforme e confluente (Figua 1A, B). Células fusiformes, de $178-226-270 \mu \mathrm{m}$ de altura e
$14-20-30 \mu \mathrm{m}$ de largura. Séries parenquimáticas de $193-252-313 \mu \mathrm{m}$ de altura e $13-25-50 \mu \mathrm{m}$ de largura, geralmente com 2 , menos comumente 3 ou 4 células. Cristais romboédricos de oxalato de cálcio de aproximadamente $25 \mu \mathrm{m}$ de comprimento, em séries de numerosas câmaras, presentes tanto na periferia das faixas de parênquima axial, como dispersas no tecido fibroso; cristais romboédricos maiores (até $80 \mu \mathrm{m}$ ), em séries de $2-6$ idioblastos, dispostos em posição semelhante (Figuras 1B, C; 2A, B).

Raios: numerosos a muito numerosos (6-9 - 11/mm), compondo 17,3\% do volume da madeira. Tecido radial homogêneo, composto inteiramente de células horizontais (Figura 2A, $\mathrm{B})$. Raios de relacionamento normal; raios agregados e fusionados, ausentes (Figura 2C, D). Raios unisseriados, pouco freqüentes $(15,7 \%$ do total); extremamente finos $(5-8,6-14 \mu \mathrm{m})$, muito baixos $(20-76-155 \mu \mathrm{m})$, com $1-6-$ 13 células de altura. Os multisseriados, em sua maioria com mais de 4 células de largura $(35,8 \%)$, menos comumente bi $(17,5 \%)$, tri $(16 \%)$ e tetrasseriados (14\%); muito baixos a baixos $(95-258-543 \mu \mathrm{m})$, com $9-19-40$ células de altura, e de finos a estreitos (14 - 42 $-75 \mu \mathrm{m}$ ), com até 8 células de largura. Células cristalíferas, envolventes, eretas, esclerosadas, latericuliformes, oleíferas e quadradas, ausentes.

Fibras: ocupando cerca de $42 \%$ do volume da madeira, distribuídas em faixas irregulares, alternadas com o parênquima axial. Fibras libriformes, não septadas, frequentemente gelatinosas e com pontoações simples, diminutas; muito curtas até curtas $(740-953-1170 \mu \mathrm{m})$, estreitas $(11-14-20 \mu \mathrm{m})$ e de paredes delgadas $(1,8-3,4-4,4 \mu \mathrm{m})$.

Outros caracteres: canais secretores, tubos laticíferos e taniníferos, líber incluso, máculas medulares e estratificação, ausentes. Anéis de crescimento demarcados por ligeira redução no diâmetro radial de fibras, parênquima axial e elementos vasculares, em estreita linha terminal (Figura 1A). 

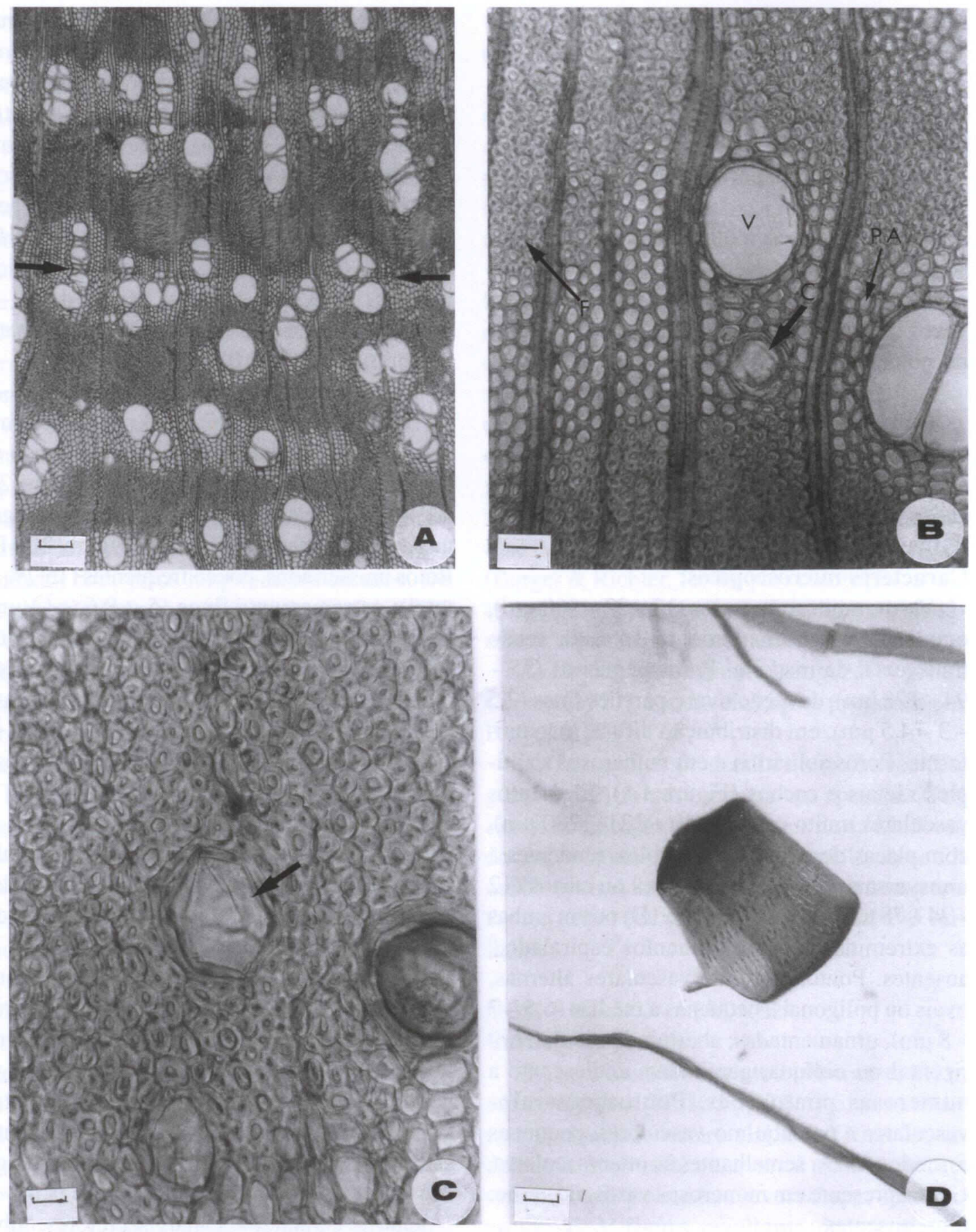

FIGURA 1 - Aspectos anatômicos da madeira de Vachellia farnesiana. A - Limite de anel de crescimento (setas), porosidade difusa e poros solitários ou em curtos múltiplos (seção transversal). B - Vaso (V), parênquima axial (PA), fibras (F) e macrocristal (C) em idioblasto (seção transversal). C - Fibras e macrocristal (seta), em detalhe (seção transversal). D - Elemento vascular com placas de perfuração simples e apêndice em uma das extremidades (macerado). Escalas $=16 \mu \mathrm{m}(\mathrm{C}, \mathrm{D}) ; 40 \mu \mathrm{m}(\mathrm{B}) ; 125 \mu \mathrm{m}(\mathrm{A})$. 

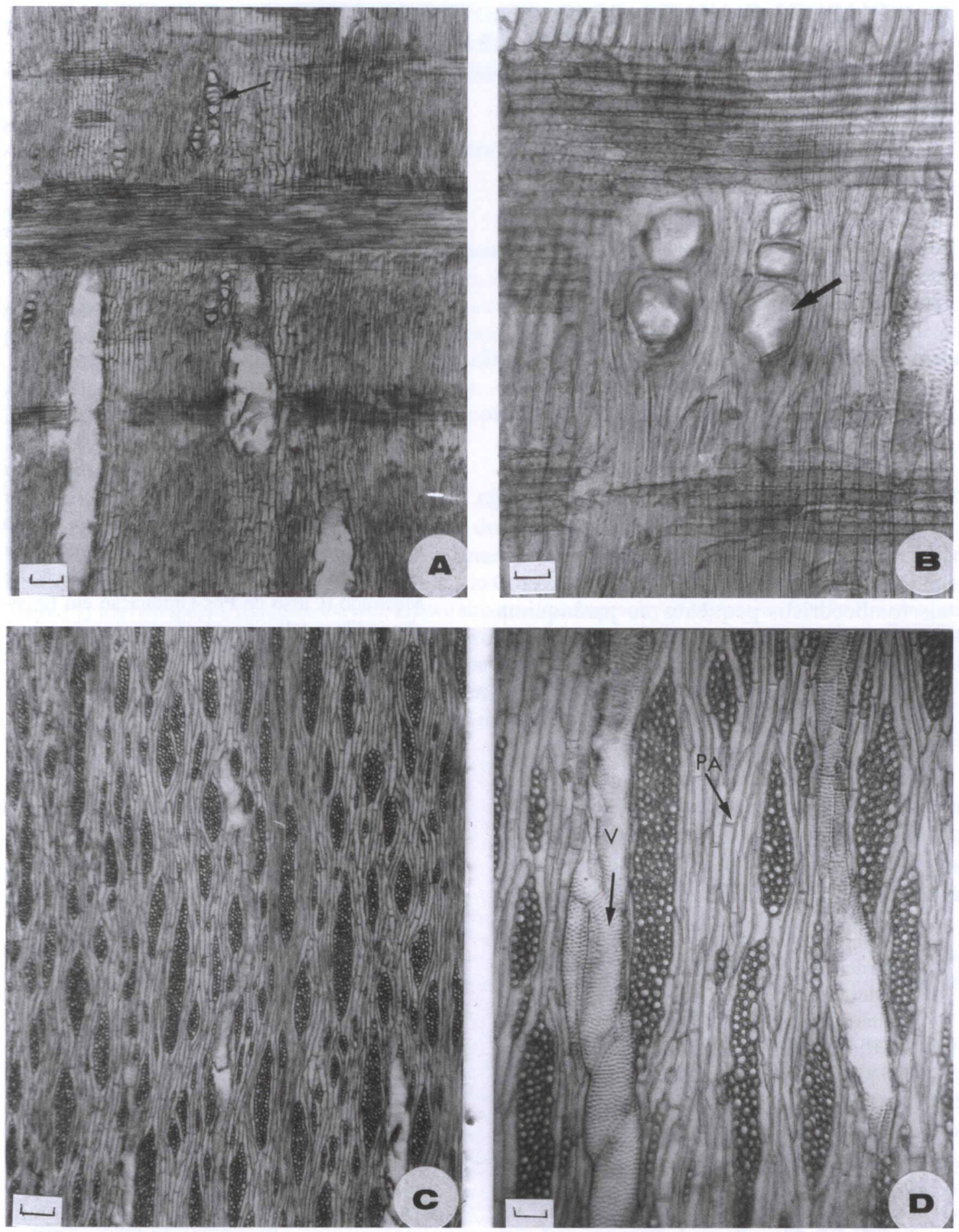

FIGURA 2 - Aspectos anatômicos da madeira de Vachellia farnesiana. A - Raios homogêneos e idioblastos com grandes cristais de oxalato de cálcio (seta) no parênquima axial (seção longitudinal radial). B - Raios homogêneos e séries axiais de idioblastos cristalíferos (seta), em seção longitudinal radial. C - Aspecto geral da madeira, em seção longitudinal tangencial. D - Raios multisseriados largos, vasos (V) e parênquima axial (PA), em seção longitudinal tangencial. Escalas $=40 \mu \mathrm{m}(\mathrm{B}) ; 54 \mu \mathrm{m}(\mathrm{D}) ; 125 \mu \mathrm{m}(\mathrm{A}, \mathrm{C})$. 
ANÁLISE DA ESTRUTURA ANATÔMICA

A presença de fibras não septadas e de paredes espessas, aliado a parênquima axial abundante e de paredes contrastantemente finas, composto por séries de 2 , raro 3 células, são detathes comuns a Vachellia farnesiana, V. caven e $V$. ibirocayensis. Este conjunto de caracteres anatômicos, de alto valor diagnóstico, permite uma fácil identificação de Vachellia, distinguindo suas espécies de todas as outras do antigo gênero Acacia, nativas no Rio Grande do Sul.

De Vachelia caven, a espécie em estudo separa-se por ter elementos vasculares mais longos (221 um; $167 \mu \mathrm{m}$ em $V$. caven $)$ e raios mais numerosos (9/mm; 6/mm em V. caven); em ambas as espécies, todavia, predominam raios com mais de 4 células de largura e cristais romboédricos grandes no parênquima axial (até $80 \mu \mathrm{m})$. Vachellia ibirocayensis, por sua vez, distingue-se das outras duas pelos raios predominantemente unisseriados e por ter apenas cristais romboédricos pequenos no parênquima axial (cerca de $25 \mu \mathrm{m}$ ).

\section{REFERÊNCIAS BIBLIOGRÁFICAS}

BANFI, E; GALASSO, G. New combinations in Vachellia Wight \& Arn., formerly Acacia Mill. s.s. (Fabaceae). Atti Soc. It. Sci. Nat. Museo Civ. Stor. Nat. Milano, v. 149, n. 1, p. 149-150, 2008.

BLACK, J.M. Flora of South Australia. Adelaide: Government Printer, 1964. 683 p.

BURGER, L.M. Estudo anatômico do xilema secundário de sete espécies do gênero Dalbergia Leguminosae Faboideae. Curitiba, Universidade Federal do Paraná, 1979. 184 p. Dissertação de Mestrado (Curso de Pós-Graduação em Engenharia Florestal).

BURGER, L.M.; RICHTER, H.G. Anatomia da madeira. São Paulo: Editora Nobel, 1991. 154 p.

BURKART, A. Leguminosas. In: DIMITRI, M.J. Enciclopedia argentina de Agricultura y Jardineria. Buenos Aires: ACME, 1978. v. 1. p. 467-538.

BURKART, A. Leguminosas Mimosóideas. In: REITZ, P.R. Flora Ilustrada Catarinense. Itajaí: Herbário Barbosa Rodrigues, 1979. 299 p.

CIALDELLA, A.M. El género Acacia en la Argentina. Darwiniana, San Isidro, v. 25, n. 1-2, p. 59111, 1984.
COPANT. Comissão Panamericana de Normas Técnicas. Descrição macroscópica, microscópica e geral da madeira - Esquema I de recomendação. Colômbia, 1973. 19 p. (COPANT 30).

COZZO, D. Anatomia del leño secundario de las leguminosas mimosoideas y caesalpinoideas argentinas silvestres y cultivadas. Rev. Inst.Nac. Invest. Ci. Nat. C. Bot., v.2, n.2, p. 63-290, 1951.

IZAGUIRRE, P.; BEYHAUT, R. Las Leguminosas en Uruguay y regiones vecinas. Montevideo: Editorial Hemisfério Sur, 2003. 301 p.

KODELA, P.J.; WILSON, P.G. New combinations in the genus Vachellia (Fabaceae: Mimosoideae) fromAustralia. Telopea, v. 11, n. 2, p. 233-244, 2006.

LORENZI, H. Árvores brasileiras. Manual de identificação e cultivo de plantas arbóreas do Brasil. Nova Odessa: Editora Plantarum, 1998. p. 158.

MARCHIORI, J.N.C. Estudo anatômico do xilema secundário e da casca de algumas espécies dos gêneros Acacia e Mimosa, nativas no Estado do Rio Grande do Sul. Curitiba: Universidade Federal do Paraná, 1980. 225 p. Dissertação de Mestrado (Curso de Pós-Graduação em Engenharia Florestal).

MARCHIORI, J.N.C. Anatomia da madeira e casca do espinilho, Acacia caven (Mol.) Mol. Ciência Florestal, Santa Maria, v. 2, n. 1, p. 27-47, 1992.

MARCHIORI, J.N.C. Estudo anatômico do xilema secundário de Acacia ibirocayensis Marchiori (Leguminosae Mimosoideae). Ciência e Natura, Santa Maria, n. 15, p. 149-159, 1993.

PIO CORRÊA, M. Dicionário das plantas úteis do Brasil e das exóticas cultivadas. Rio de Janeiro: Imprensa Nacional, 1984. v. 2. 707 p.

SEIGLER, D.S.; EBINGER, J.E. New combinations in the genus Vachellia (Fabaceae: Mimosoideae) from the New World. Phytologia, n. 87, p. 139178, 2006.

SOBRAL, M.; JARENKOW, J.A.; BRACK, P.; IRGANG, B.; LAROCCA, J.; RODRIGUES, R.S. Flora arbórea e arborescente do Rio Grande do Sul, Brasil. São Carlos: RiMa: Novo Ambiente, 2006. $350 \mathrm{p}$.

TORTORELLI, L. A. Maderas y bosques argentinos. Buenos Aires: ACME, 1956.910p.

WIEDENBRUG, W. Maderas chilenas. Contribuición a su anatomia y identificación. Lilloa, Tucumán, n. 16, p. 262-375, 1948.

WIGHT, R.; ARNOTT, G. Prodromus Florae Peninsulae Indiae Orientalis. London, 1834. p. 272. 